Universidad de Lima

Facultad de Comunicación

Carrera de Comunicación

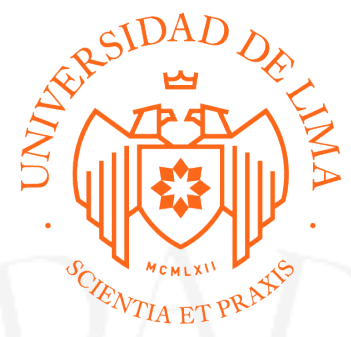

\title{
MONÓLOGOS SOBRE LA VERDAD
}

Trabajo de Suficiencia Profesional para optar el Título Profesional de Licenciado en Comunicación

\section{Paolo Alexis Ramirez Ramirez}

Código 20090942

$$
\text { Lima - Perú }
$$

12 de Mayo de 2019 


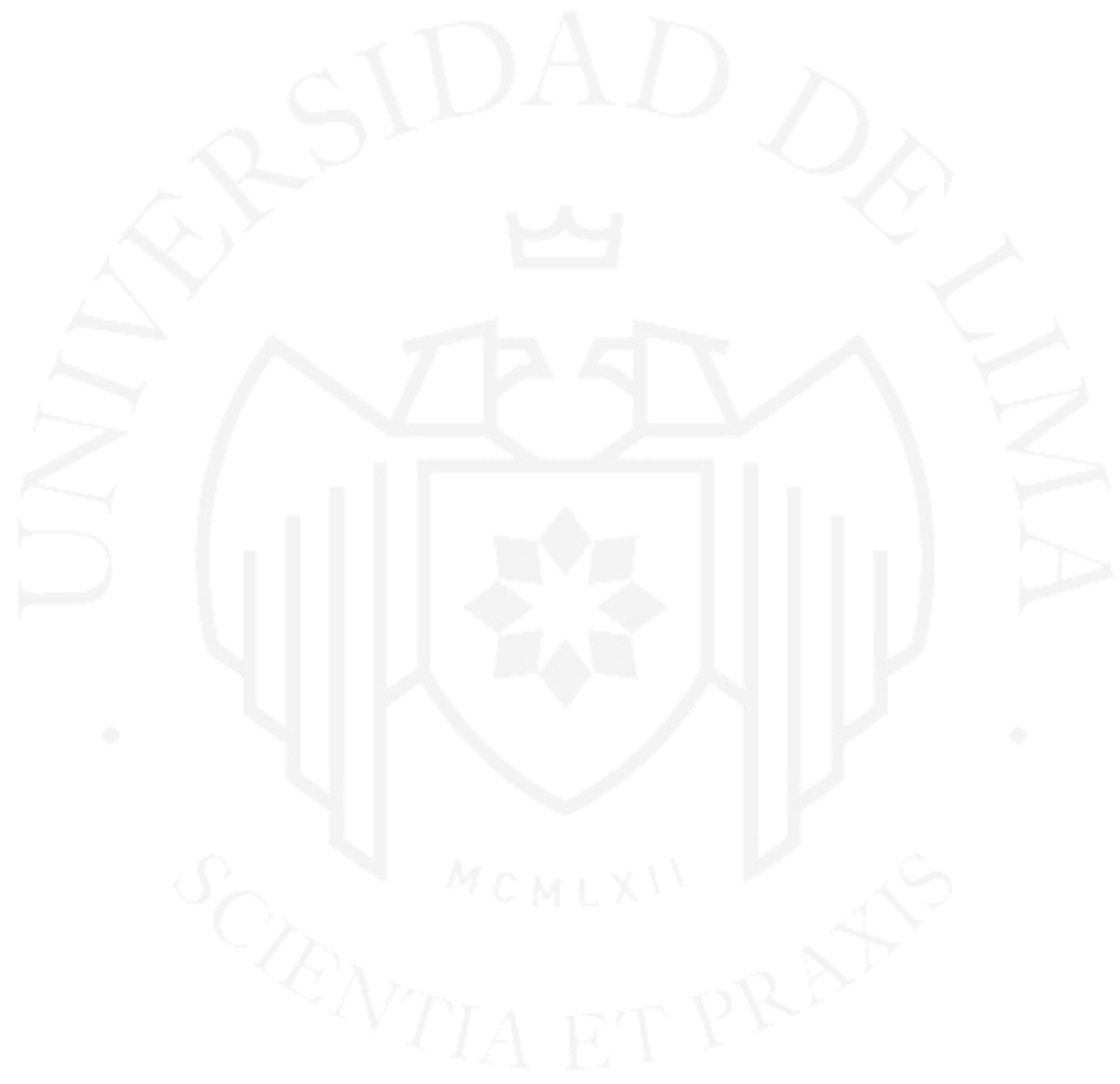


MONÓLOGOS SOBRE LA VERDAD 


\section{ÍNDICE}

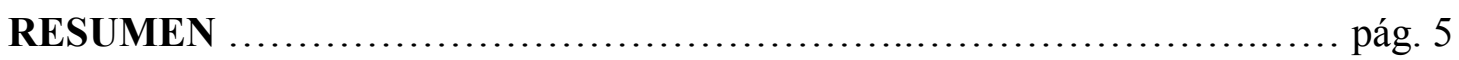

INTRODUCCIÓN ................................................ pág. 6

1. ANTECEDENTES DEL TRABAJO ................................... pág. 7

1.1 Investigación de campo .................................... pág. 7

1.2 Documentales de referencia ................................. pág. 13

2. PROPUESTA DE COMUNICACIÓN ................................. pág. 15

2.1 Justificación de punto de vista ................................. pág. 15

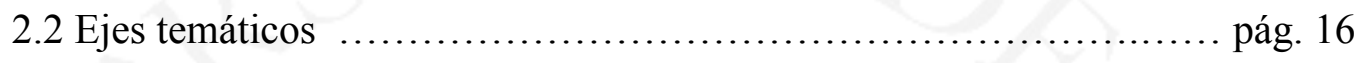

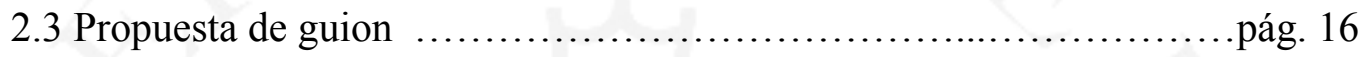

2.3 Propuesta de cuestionario .......................................pág. 18

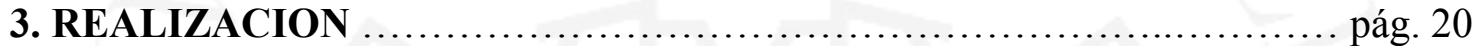

3.1 Presupuesto de producción ....................................... pág. 20

3.2 Plan de rodaje ...............................................pág. 21

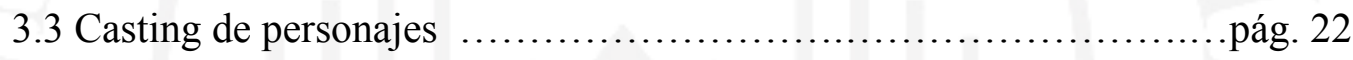

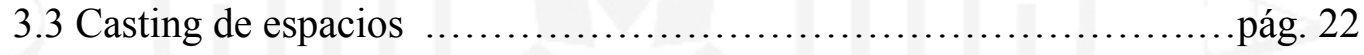

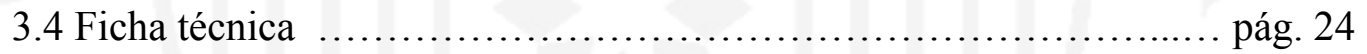

REFERENCIAS ......................................................... 26 


\section{RESUMEN}

Para la realización de este documental se decidió tratar el tema de la discriminación desde los monologos de Walter Chullo, un comediante de stand up comedy que basa su material en situaciones cotidianas de racismo, generando la reflexión de manera espontanea en su público. 


\section{INTRODUCCIÓN}

La I Encuesta Nacional sobre Percepciones y Actitudes sobre Diversidad Cultural y Discriminación Étnico - Racial del Ministerio de Cultura señala que más de la mitad de peruanos se han sentido discriminados o muy discriminados en algún momento. La ausencia de una estrategia concreta de parte del Estado para abordar este tema, exige que se usen otros escenarios de reflexión.

"Monólogo sobre la verdad" es un documental que expone cómo el humor puede ser una herramienta para concientizar sobre un problema social: la discriminación.

A través de los monólogos de Walter Chullo se logra la reflexión involuntaria del público, que junto a la risa, ofrece una nueva perspectiva para analizar un comportamiento que tanto daño nos hace como peruanos. A diferencia de otros estilos de humor, el stand up comedy tiene como premisa la verdad. El comediante hace uso de situaciones reales, que muchas veces son familiares para el público, y es muy probable que logren identificarse. 


\section{ANTECEDENTES DEL TRABAJO}

1.1 Investigación de campo

En el año 1960, y en el marco de la Convención relativa a la Lucha contra las Discriminaciones en la Esfera de la Enseñanza, la $\mathrm{UNESCO}^{1}$ definió a la discriminación como "toda distinción, exclusión, limitación o preferencia, fundada en la raza, el color, el sexo, el idioma, la religión, las opiniones políticas o de cualquier otra índole, el origen nacional o social, la posición económica o el nacimiento...” (UNESCO, 1960)

En el Perú existe una ley que sanciona la discriminación. La Ley Contra Actos de Discriminación, muestra sus efectos a través del articulo 323 del Código Penal peruano, donde se tipifica el delito de discriminación de la siguiente manera:

"El que, por sí o mediante terceros, discrimina a una o más personas o grupo de personas, o incita o promueve en forma pública actos discriminatorios, por motivo racial, religioso, sexual, de factor genético, filiación, edad, discapacidad, idioma, identidad étnica y cultural, indumentaria, opinión política o de cualquier índole, o condición económica, con el objeto de anular o menoscabar el reconocimiento, goce o ejercicio de los derechos de la persona, será reprimido con pena privativa de libertad no menor de dos años, ni mayor de tres o con prestación de servicios a la comunidad de sesenta a ciento veinte jornadas "

Una de las expresiones de la discriminación es el racismo. El cual se fundamenta en una supuesta superioridad sobre otra persona, o grupo de personas, originada en la raza.

En el Perú, solo el 8\% se considera a sí mismo como racista, según la I Encuesta Nacional sobre Percepciones y Actitudes sobre Diversidad Cultural y Discriminación Étnico Racial del Ministerio de Cultura. En esta misma encuesta, dentro de sus principales resultados, se puede leer que el $53 \%$ de peruanos considera a los mismos peruanos como racistas o muy racistas. Esto, muestra una percepción incongruente sobre la consideración que tenemos sobe nosotros mismos como racistas, ya que consideramos al otro como tal, pero no nosotros. Esta no es una situación actual, Callirgos, en 1993 escribía lo siguiente:

El racismo puede tener formas muy sutiles e indirectas: puede incluso proteger la idea de que uno no tiene prejuicios y no discrimina. Especialmente en sociedades en las cuales de alguna manera -no necesariamente legal- se sanciona la discriminación, los individuos racistas tratarán de negarse a sí

\footnotetext{
${ }^{1}$ UNESCO. Organización de las Naciones Unidad para la Educación, la Ciencia y la Cultura.
} 
mismos los sentimientos racistas y tratarán de cuidarse ante los demás, y ante sí mismos, de no demostrarlo (Callirgos. 1993, p. 144).

Esta situación es grave, ya que demuestra una normalización del racismo. Una normalización que he llegado a un punto en el cual no deja que nos consideremos como tales.

Las manifestaciones de esta exclusión dentro de la colectividad son frecuentes y se encuentran presentes en los diversos ámbitos de nuestra sociedad generando que la discriminación sea percibida como un modo natural de descartar a determinadas personas (Sánchez. 2010, p. 73)

Así mismo, y como mencionaba Callirgos, el racismo se expresa de distintas maneras, algunas hasta sutiles, como ese sentimiento de paternidad que se pueda tener por sobre personas que consideramos inferiores por su lugar de origen, color de piel, etc.

Callirgos (1993) señala: "Clasificarse racialmente implica ir en contra del valor de igualdad, pues al existir una conocida "jerarquía racial”, clasificar significa ubicar(se) en una posición definida: "arriba o abajo” (p. 156). Si bien, siempre se habla de que todos somos iguales, sería importante definir “en que" es que somos iguales. Las leyes entienden que no todas las personas son iguales y es por eso que por ejemplo existen dentro del Código Civil distintos libros sobre distintos "tipos" de personas. Y es que reconocernos como iguales podría traer complicaciones, lo cierto es que la igualdad de la que siempre se habla es una igualdad en "dignidad". Es por eso, que en la Constitución Política del Perú (1993) el primer artículo hace referencia a "la defensa de la persona humana y el respeto de su dignidad son el fin supremo de la sociedad y del Estado”. Mientras que en el segundo punto del articulo dos dice: "Toda persona tiene derecho a la igualdad ante la ley. Nadie debe ser discriminado por motivo de origen, raza, sexo, idioma, religión, opinión, condición económica o de cualquier otra índole”.

Como vemos, la noción de igualdad debe entenderse como igualdad en dignidad, en algunos casos como igualdad frente a la ley. Ya que en algunas ocasiones, los sujetos de derechos no son iguales frente a la ley. Lo cierto es que la discriminación, y para motivos de esta investigación, el racismo, tienen más complicaciones que las que uno podría imaginar que genera en una o un grupo de personas.

En un país diverso y escindido como el Perú, el racismo es un problema fundamental. Impone barreas a la comunicación, impidiendo así la construcción 
de una identidad y de un proyecto nacional democrático basado en el respeto y la justicia (Callirgos. 1993, p. 17).

Al ser el Perú un país diverso, lo son también diversas sus culturas. Y son a su vez estas diferencias las que son usadas de burla y refuerzan el racismo. Para motivos de esta investigación entenderemos a la cultura como:

Una cultura es un conjunto de formas y modos adquiridos de concebir en mundo, de pensar, de hablar, de expresarse, percibir, comportarse, organizarse socialmente, comunicarse, sentir y valorarse a uno mismo en cuanto individuo y en cuanto a grupo. Es intrínseco a las culturas el encontrarse en un constante proceso de cambio (Heise, María y otros. 1994, p. 7).

$\mathrm{Y}$ es que, siguiendo estas pautas, podríamos ver claramente que el Perú es un país pluricultural. Un país que tiene como sus principales virtudes a su riqueza cultural, pero también como uno de sus principales flagelos, ya que esto hace que el sentido de identidad sea más complicado de fortalecer en la actualidad, y de cara al bicentenario. Han pasado muchas décadas dándole la espalda a la cultura, que ha generado que cada vez nos sintamos más cercanos a lo extranjero y más lejano a lo nuestro. Muchos inclusive hablan de estas diferencias culturales como si fueran el origen de conflictos. Respecto a esto, INDEPA $^{2}$, en su libro “Aportes para un enfoque intercultural”, menciona:

Las diferencias culturales, muy por el contrario a lo que se piensa, cuando se les da una correcta orientación, no genera conflictos sociales, económicos, ni políticos. Éstos, más bien, ofrecen sólidos argumentos que respaldan la búsqueda de formas de "disfrutar de nuestras diferencias" y de sentirnos orgullosos de ser lo que somos (INDEPA. 2013, p. 43)

Es por eso que, el reconocernos como diferentes es fundamental para poder crear una identidad. Aceptar al país, con todas sus mezclas de cultura será el paso inicial para eliminar el racismo. Y depende de los gobiernos trabajar en esta interculturalidad, buscar similitudes y diferencias entre estas, generar objetivos comunes y crear políticas de gobierno que ayuden a conseguirlas.

La interculturalidad. Acepta la diversidad cultural, indica que es inevitable la influencia de unas culturas sobre otras, y en el mejor de los casos deviene en el enriquecimiento de las mismas culturas particulares. Esta interrelación, para que sea intercultural, deberá buscar puntos coincidentes, de manera consciente, buscando objetivos comunes para así obtener ciertos logros, en forma más eficaz

\footnotetext{
2 Instituto Nacional de Desarrollo de los Pueblos Andinos y Amazónicos.
} 
aunque con previa selección de los elementos culturales que se combinan o convergen a fin de obtener mejores calidades de vida a favor de los actores involucrados (INDEPA. 2013, p. 3)

La ausencia de políticas orientadas a la interculturalidad ha provocado que el racismo, y la discriminación en general, sea un problema mayúsculo. Según la I Encuesta Nacional sobre Percepciones y Actitudes sobre Diversidad Cultural y Discriminación Étnico Racial del Ministerio de Cultura, más de la mitad de peruanos/as se ha sentido discriminado o muy discriminado, y el 14\% de estos, menciona que la razón por la que fue discriminado fue "por sus costumbres".

A su vez, el 59\% de peruanos "percibe que la población quechua y aimara es discriminada o muy discriminada siendo las principales causas su forma de hablar, vestimenta e idioma o lengua que habla"s.

Si bien, la persona más afectada en estos casos, son aquellos que sufren de discriminación/racismo, no debemos olvidar que esto es un especie de circulo vicioso, y que al final, en el Perú todos terminan siendo discriminados y discriminadores. Es por eso que Bruce describe al racismo como:

“... propio racismo como estado permanente de crisis que detiene el crecimiento individual y colectivo de todos, pues tanto los discriminados como los discriminadores terminan siendo víctimas" (Bruce. 2007, p. 55)

Hay que recordar siempre, que el racismo tiene consecuencias no solo en la victima y el victimario, sino en toda la sociedad. Parte de la normalización del racismo y la discriminación se ve expresada mediante el humor. Y es que en nuestro país hay mucha costumbre de un humor basado en la burla hacia al otro, y mucha de esta burla se justifica en el aspecto racial.

En realidad, el humor de contenido racial no sólo revela estereotipos y prejuicios sino los profundos complejos de nuestra sociedad. Lo blanco es asociado a lo bello y superior, con mayor prestigio para la percepción común. Por el contrario, lo oscuro a lo feo, inferior y vulgar. Esto provoca implicancias graves en el imaginario colectivo pues estos rasgos son objeto de valoraciones estéticas negativas que, por cierto, son los de la mayoría de peruanos (Sánchez. 2010, p. 54 $-55)$

\footnotetext{
${ }^{3}$ I Encuesta Nacional sobre Percepciones y Actitudes sobre Diversidad Cultural y Discriminación Étnico - Racial, 2018. Ministerio de Cultura.
} 
Algunos ejemplos de humor con contenido racial se aprecian en los programas cómicos de fin de semana. Donde la presencia de personajes como "El negro mama" y "La Paisana Jacinta" marcaron uno de los puntos más críticos de los programas cómicos de señal abierta. Sin embargo, no habría que olvidar que en los 90's, los cómicos ambulantes basaban su humor tanto en el aspecto racial como en la agresión física.

Lo cierto es que muchos de estos personajes y estas actitudes han ido desapareciendo, esto gracias al fortalecimiento de la Ley Contra la Discriminación, pero también por la presión que ejercen algunas agrupaciones para que las manifestaciones racistas y discriminadores sea extirpadas de la televisión, y en general de todo medio de comunicación y la sociedad.

El racismo discursivo abierto ha desaparecido en los medios de comunicación. Sin embargo, lo que puede observarse es una manifestación más sutil e indirecta en los programas cómicos $\mathrm{y}$, en particular, en la broma con contenido racial (Sánchez. 2010, p. 101)

Como menciona Sánchez, el racismo discursivo abierto va desapareciendo casi por completo, sin embargo, deja el espacio para que otros tipos de humor aparezcan, algunos todavía con muestras racistas, aunque más sutilmente. Y es que en muchos casos, como menciona Sánchez también, el humor ha sido un vehículo idóneo para formar posturas críticas respecto a la realidad social (Sánchez. 2010, p. 126)

Y es ese el valor fundamental del humor. Que sirva como vehículo para la crítica y la reflexión, sin embargo, debe seguir siendo humor. Entonces un humor, que sea solo crítico o reflexivo, puede que no sea tan impactante como se desee.

Uno de los tipos de humor preferidos para la crítica, en especial política, ha sido la parodia basada en imitación. Aquí en Perú hemos tenido exponentes en medios de comunicación como "Los Chistosos" que han marcado la pauta del humor en la radio, sin embargo aún ahí, se puede apreciar bromas con contenido racial o inclusive en la presentación de sus personajes, remarcando las formas de hablar, los acentos, o su inteligencia.

En la actualidad, un estilo de humor viene ganando adeptos en el país es el stand up comedy. Este formato trata de un comediante que se presenta frente al público con un 
monologo cargado de dosis de humor. Pero lo importante a resaltar, y el motivo por el cual nos centramos en este estilo para esta investigación, es que para escribir un monólogo para stand up comedy, este debe nacer de la verdad del propio comediante. De su pasado. A diferencia de otros tipos de humor, donde se basa en la imitación, interpretación o actuación, en el stand up comedy es el mismo comediante, sin personaje, el que se enfrente al público al cual le contará sus verdades.

Judy Carter define al stand up comedy como la comedia personal: "La nueva escuela de hacer comedia es la comedia personal. Tu actuación tiene que ver contigo: los asuntos que sientes en tus entrañas, tu cuerpo, tu matrimonio, tu divorcio, tus hábitos de droga..." (Carter. 1989, p. 3)

La importancia de la verdad, en este estilo de comedia, es fundamental. Ya que la legitimidad que tengas sobre un tema se gana por la probabilidad de que esta sea así. Que un joven de 20 años hable de sus años de matrimonio, es poco probable, por ende, termina siendo poco creíble para el público y poco gracioso a la vez. Así mismo, un aspecto que va de la mano, es la perdida de status. Al ser situaciones reales, suelen ser situaciones en las cuales el personaje sufre una serie de inconvenientes.

"Uno de los principales errores de percepción sobre lo que resulta cómico proviene de entender que su fuente tiene necesariamente que ser alguien que está allá arriba... para nada... es bastante más interesante contemplar a alguien en el proceso de lidiar con sus problemas que no a alguien que aparenta una espiritualidad impecable y sabelotodo... El truco es estar dispuesto a exhibirte a ti mismo" (Carter. 1989, p. 4)

Para motivos de esta investigación, se usarán los monólogos de Walter Chullo.

Chullo es un comediante proveniente del Cusco con más de 10 años de experiencia, con base en el clown. Sus monólogos se basan en situaciones cotidianas que le suceden, sin embargo, estas situaciones también estar cargadas de racismo. 


\subsection{Documentales de referencia}

- You lought, but it's true (2011) - David Paul Meyer

Este documental muestra como Trevor Noah, un joven comediante sudafricano, se prepara para su primer unipersonal basando su monologo en las experiencias de su infancia, siendo parte de una familia birracial durante el apartheid en Sudáfrica.

Este documental se tomó como referencia ya que guarda aspectos similares a los que se plantean en este trabajo, por ejemplo: hacer comedia habiendo crecido en un ambiente hostil. Noah creció en un país inmerso en una crisis social violenta que conllevo a una revolución en su país. Periodos cargados de odios y persecuciones por el color de piel, que en la actualidad aún no han sido superados. Chullo, paso su juventud en el Cuzco durante la época del terrorismo en el Perú. Una época marcada por el terror, pero también por la migración de las personas del campo a la ciudades, que conllevo en un choque cultural.

Además, la búsqueda de Noah de crear material en base al racismo sufrido, pero también reflexionado sobre hasta cuando se seguirá hablando del racismo para la base del humor en su país. Chullo también reflexiona sobre el racismo y lo usa de base para gran parte de sus monólogos, sin embargo, la mayor similitud entre ambos es que los dos quieren lograr algo a través de la comedia. No solo reflexionar ellos para crear su material, sino también que el público haga una reflexión, para avanzar como sociedad.

- Ticling Giants (2016) - Sara Taksler

Este documental revela las innumerables presiones a las que es sometido un comediante egipcio por desafiar a las autoridades de su país mediante la sátira en televisión.

Si bien este documental presenta el desarrollo de Bassem Youssef, un cirujano que se convierte en el principal personaje de la televisión egipcia, para motivos de esta investigación se tomó de referencia por como muestra el impacto que tiene la comedia en su público. Al igual que Chullo, Youssef es claro al decir que 
prefiere "reírse de las diferencias en lugar de odiarse", y su público, en inicio, lo entiende y lo asimila de esa manera.

En Tickling Giants, se escucha a un ciudadano egipcio decir: "la comedia hace divertida las cosas negativas", cuando se le pregunta por el programa de Bassem Youssef. Y es esta la premisa bajo la cual Chullo genera su material, reírse de la diferencias para poder avanzar.

- Dying Laughing (2016) - Paul Toogood, Lloyd Stanton.

Este documental recorre los momentos claves en la carrera de los comediantes, contados por ellos mismos. Explican cómo escriben sus textos, sus fracasos, lo que buscan generar y como la comedia, en algunos casos, los salva de la depresión. Además, muestra como ellos aceptan la responsabilidad de pararse frente a un público y tener la capacidad de hacer que cambien su forma de pensar, y la responsabilidad que eso conlleva.

Este documental se toma como referencia para generar el acercamiento con el comediante. Analizar las respuestas de los entrevistados sirve para adentrarse en la mente de un comediante y poder crear un cuestionario adecuado para los objetivos de la investigación. 


\section{PROPUESTA DE COMUNICACIÓN}

2.1 Justificación de punto de vista

El Perú es un país altamente racista, y las estadísticas lo demuestran. Más de la mitad de peruanos se han sentido discriminados o muy discriminados, según los resultados de la I Encuesta Nacional sobre Percepciones y Actitudes sobre Diversidad Cultural y Discriminación Étnico - Racial del Ministerio de Cultura. En un país con estos resultados, la discriminación, y en específico el racismo, suele ser un tema que se toca solo cuando es denunciado. Sin embargo, el dialogo para su erradicación no se da por parte de entidades públicas o privadas. Por eso, cualquier espacio de dialogo o reflexión sobre estos temas será siempre valorado.

El humor, es una herramienta que ha servido para criticar gobiernos, situaciones puntuales de racismo, o ridiculizar a personajes públicos. Pese a que su objetivo puede ser válido, muchas veces se hacen usando estereotipos negativos que solo fortalece la exclusión y burla sobre las poblaciones continuamente discriminadas.

En ese sentido, para motivos de esta investigación se decidió basar el documental en los monólogos de Walter Chullo, un comediante cusqueño con más de 10 años de experiencia. Walter utiliza las situaciones cotidianas de racismo que sufre para crear sus rutinas de humor. Al exponerlas al público, genera de manera espontánea una reflexión frente a estas situaciones.

La decisión de tomar a este tipo de humor como base para este trabajo pasa porque la premisa fundamental del stand up comedy es la verdad. Si no hay verdad, no genera risas. Walter, nació en una comunidad campesina de Cusco, lo cuenta, y lo demuestra con cada detalle que va contando en su monólogo. Gana legitimidad frente al público. Las situaciones que cuenta son reales, pero en lugar de contarlos a manera de denuncia, lo cuenta en código de comedia. Esto no solo sirve para bajar la tensión frente a los actos de discriminación, sino que también para que el público reflexione frente a estos, aunque no sea de manera obligatoria. Reírse de cómo a una persona le revisan la mochila solo por tener rasgos físicos diferentes es potente. Es una situación real que sucede todos los días y a veces solo se deja pasar. 


\subsection{Ejes temáticos}

Los ejes temáticos tratados en el documental fueron los siguientes:

Discriminación en el Perú.

Racismo y normalización de este.

La verdad como fuente de humor.

Humor étnico como reforzador de estereotipos.

Stand up comedy como estilo de comedia.

Espacios públicos para la reflexión.

Reírse de los problemas para avanzar.

Al ser un documental testimonial, todos estos ejes son abordados por el entrevistado mediante la entrevista realizada y sus monólogos presentados. El personaje muestra como él, supera las situaciones de discriminación usándolas como fuente de inspiración para sus monólogos, a su vez, presentados al público, como pueden generar la reflexión sobre su público.

El personaje no solo es víctima de discriminación, también es un gestor involuntario que usas las situaciones de racismo sufridas para promover la reflexión frente a este tema.

\subsection{Propuesta de guion}

\section{PRESENTACIÓN. COCODRILO VERDE. NOCHE}

Audios e imagen de la entrada al escenario de Walter Chullo para realizar su monologo, y su primer gag ${ }^{4}$.

\section{PRESENTACIÓN DE WALTER. DEPARTAMENTO. DÍA}

Presentación de sí mismo en la entrevista. Apoyos de la decoración de su departamento.

\section{ESCENARIO. COCODRILO VERDE. NOCHE}

\footnotetext{
${ }^{4}$ RAE. Gag: Efecto cómico rápido e inesperado en un filme o en otro tipo de espectáculo.
} 
Alternar imágenes de la entrevista con fragmentos de sus monólogos donde se muestre el uso de la situaciones de discriminación para su rutina de humor.

4.- ENTREVISTA. DEPARTAMENTO. DÍA

Entrevista con Walter donde se aborda la importancia de hablar sobre discriminación y las situaciones donde ha sido víctima.

\section{ESCENARIO. COCODRILO VERDE. NOCHE}

Alternar imágenes de la entrevista con fragmentos de sus monólogos donde se muestre el uso de la situaciones de discriminación para su rutina de humor.

\section{ENTREVISTA. DEPARTAMENTO. DÍA}

Tema: la importancia del humor en la sociedad, su estilo de humor y sus alumnos.

Apoyos de él dictando clases

\section{ENTREVISTA. LA POSADA DEL MIRADOR. DÍA}

Se toca el tema de su unipersonal, el tipo de humor que tienen los peruanos.

\section{ENTREVISTA. DEPARTAMENTO. DÍA}

Tema: Bases del stand up comedy.

\section{ESCENARIO. COCODRILO VERDE. NOCHE}

Alternar imágenes de la entrevista con fragmentos de sus monólogos donde se muestre el uso de la situaciones de discriminación para su rutina de humor.

\section{ENTREVISTA. DEPARTAMENTO. DÍA}

Tema: La importancia de la verdad para el stand up comedy.

\section{ESCENARIO. COCODRILO VERDE. NOCHE}

Alternar imágenes de la entrevista con fragmentos de sus monólogos donde se muestre el uso de la situaciones de discriminación para su rutina de humor.

\section{ENTREVISTA. DEPARTAMENTO. DÍA}

Tema: Reflexión sobre la relación entre el humor y la discriminación. 


\section{ESCENARIO. COCODRILO VERDE. NOCHE}

Monologo sobre problemas como país y fin de la presentación.

\subsection{Propuesta de cuestionario}

Para el cuestionario se trabajó con 3 grandes ejes temáticos, de los cuales se van desprendiendo los más específicos detallados anteriormente. Las preguntas realizadas se fueron alternando entre ejes a lo largo de las dos entrevistas realizadas.

Personales:

¿Cuál es tu nombre y donde naciste?

¿Desde cuando vives en Lima?

¿Cómo es el lugar donde naciste y si lo extrañas?

¿Te gusta vivir en Lima?

Discriminación:

¿Crees que es importante hablar sobre la discriminación? ¿Por qué?

¿Consideras que el humor de los peruanos se basa mayoritariamente en la burla hacia el otro?

¿Has sufrido de discriminación?

¿Qué opinas de los programas cómicos de tv donde usan sketch?

¿Qué opinas de la paisana Jacinta, el negro mama, las pitucas de la molina?

¿Crees que el racismo dificulte la idea de crear una "identidad peruana"?

¿Crees que el ser cusqueño te ha abierto o cerrado puertas en Lima?

Humor

¿Cuáles son las bases del stand up comedy?

¿Recomendarías hacer stand up comedy? ¿Por qué?

¿Cuál es el público de tu humor?

¿Qué haces cuando un "gag” no funciona? 
¿Qué es lo más importante al pararte en el escenario: la apariencia, la personalidad, el texto?

¿Cómo el humor puede ayudar contra la discriminación?

¿De que trataba "El Perú con Chullo"?

¿Algunos de tus monólogos han sido inspirados en situaciones de discriminación?

¿Crees que tu humor puede ser "discriminador"?

¿Sientes una responsabilidad frente a tu público, más allá de hacerlos reír? ¿Alguna vez no te han dejado presentarte en un escenario?

¿Alguna vez te pidieron que no toques algún tema en específico?

¿Cómo el stand up comedy te ayudo a ti? 


\section{REALIZACION}

3.1 Presupuesto de producción

\begin{tabular}{|c|c|c|c|c|}
\hline \multicolumn{5}{|c|}{ PRESUPUESTO TENTATIVO } \\
\hline \multicolumn{5}{|c|}{ DiA 1 - 27/04/19 } \\
\hline NÚMERO & DETALLE & & & DESCRIPCIÓN \\
\hline 1 & Transporte & $\mathrm{s} /$. & 25.00 & Gasolina: La Molina - Barranco - La Molina \\
\hline 2 & Estacionamiento & S/. & 15.00 & 3noras de estacionamiento en playa \\
\hline 3 & Almuezo & $\mathrm{S} /$. & $\angle 5.00$ & Almuezo en Borranco para dos personas \\
\hline
\end{tabular}

Subtotal S/. $\quad 95.00$

\begin{tabular}{|c|c|c|c|c|}
\hline \multicolumn{5}{|c|}{ PRESUPUESTO TENTATIVO } \\
\hline \multicolumn{5}{|c|}{ D[A 1 - 30/04/19 } \\
\hline NÚMERO & DETALLE & & & DESCRIPCIÓN \\
\hline 1 & Transporte & $5 /$. & 25.00 & Gasolinas La Molina - Miraflores - La Molina \\
\hline 2 & Estacionamiento & $\mathrm{s} /$. & $1<.00$ & 2 horas de estacionamiento en playa \\
\hline 3 & Pago a segundo equipo & S/. & 90.00 & Angel Fonseca + Canon T4i \\
\hline 4 & Regalo a entrevistado & $\mathrm{S} /$. & 15.00 & Bolss de cáfé orgánico \\
\hline 5 & Alquiler de microfono & $\mathrm{S} /$. & 50.00 & Alquiler de microfono pechero Rhode \\
\hline
\end{tabular}

Subtotal $\quad$ S/. 219.00

\begin{tabular}{|c|c|c|c|c|}
\hline \multicolumn{5}{|c|}{ PRESUPUESTO TENTATIVO } \\
\hline \multicolumn{5}{|c|}{ DiA $1-04 / 05 / 19$} \\
\hline NÚMERO & DETALLE & & $\mathrm{ClO}$ & DESCRIPCIÓN \\
\hline 1 & Transporte & $\mathrm{s} /$. & 15.00 & Gasolina: La Molina - Miraflores \\
\hline 2 & Estacionamiento & $\mathrm{S} /$. & 7.00 & 1 hora de estacionamiento en playa \\
\hline 3 & Transporte & $\mathrm{s} /$. & 10.00 & Gasolina: Miratiores - Barranco \\
\hline 4 & Estacionamiento & $\mathrm{S} /$. & 10.00 & 2 horas de estacionamiento en playa \\
\hline 5 & Refrigerio & $\mathrm{S} /$. & 20.00 & Réfrigerio para dos personas \\
\hline 6 & Transporte & $\mathrm{s} /$. & 10.00 & Gasolina: Borranco - Miraflores \\
\hline 7 & Pago a segundo equipo & $\mathrm{S} /$. & 90.00 & Angel Fonseca + Canon $t 4 i$ \\
\hline 8 & Alquiler grabadora de audio & $\mathrm{s} /$. & 150.00 & Grabadora de audio Tascam + Son disk 32 gb \\
\hline 9 & Cena & $\mathrm{S} /$. & 35.00 & Cena para dos \\
\hline 10 & Transporte & $\mathrm{S} /$. & 15.00 & Gasolina: Miratlores - La Molina \\
\hline
\end{tabular}

Subtotal S/. 362.00




\begin{tabular}{|c|c|c|c|c|}
\hline \multicolumn{5}{|c|}{ PRESUPUESTO TENTATIVO } \\
\hline \multicolumn{5}{|c|}{ DIA $1-11 / 05 / 19$} \\
\hline NÚMERO & DETALLE & & & DESCRPCIÓN \\
\hline 1 & Transporte & $5 /$. & 25.00 & Gasolina: La Molina - Barranco - La Molina \\
\hline 2 & Estacionamiento & $\mathrm{s} /$. & 15.00 & 3noras de estacionamiento en playa \\
\hline 3 & Almuerzo & $\mathrm{S} /$. & $\angle 5.00$ & Almuezo en Borranco para dos personas \\
\hline
\end{tabular}

Subtotal S/. 95.00

3.2 Plan de rodaje

\begin{tabular}{|c|c|c|c|}
\hline \multicolumn{4}{|c|}{ PLAN DE RODAJE } \\
\hline \multicolumn{4}{|c|}{ DiA 1 - 27/04/19 } \\
\hline HORA & LOCACIÓN & DETALLE & EQUIPO \\
\hline $11: 00-02-00 \mathrm{PM}$ & 1 & Obrservación: Walter Chullo dando clases & Equipo 1 \\
\hline \multicolumn{4}{|c|}{ DIA 2 - 30/04/19 } \\
\hline HORA & LOCACIÓN & DETALLE & EQUIPO \\
\hline 04:00.05:00PM & 2 & Entrevista: Water Chulo & Equipo 1 \\
\hline \multicolumn{4}{|c|}{ DIA 3 - 04/05/19 } \\
\hline HORA & LOCACIÓN & DETALLE & EQUIPO \\
\hline 0L:00 - 05:00PM & 1 & Obrservación: Walter Chullo dando clases & Equipo 1 \\
\hline 08:00 - 09:30PM & 3 & Observaciónc Walter Chullo haciendo monólogo & Equipo 1 y 2 \\
\hline \multicolumn{4}{|c|}{ DiA $4-11 / 05 / 19$} \\
\hline HORA & LOCACION & DETALLE & EQUIPO \\
\hline 03:00 - 06:00PM & 1 & Obrsevvaciön: Walter Chullo dando clases & Equipo 1 \\
\hline
\end{tabular}

Leyenda:

Locación 1: La Posada del Mirador (Bar) - Calle Ermita 104 Barranco

Locación 2: Departamento de Walter Chullo - Miraflores

Locación 3: Cocodrilo Verde (Bar) - Calle Francisco de Paula Camino 226

Equipo 1: Paolo Ramirez + Cámara Canon 80D

Equipo 2: Ángel Fonseca (Asist. de cámara) + Cámara Canon t4i 


\subsection{Casting de personajes}

Al basar todo el documental en el testimonio e interpretación de Walter, él será el único personaje a considerar en el documental final.

\section{Walter Chullo (Cusco)}

Comediante de stand up comedy con más de 10 años de experiencia y con bases en el clown. Profesor de más de 10 promociones de stand up comedy. Fue conductor de televisión en Willax TV y en Panamericana Televisión. Además, fue jurado en el concurso de stand up comedy en el programa "El reventonazo de la chola".

Además, se realizaron entrevistas cortar a otros comediantes. Sin embargo, se decidió por su no inclusión en el documental final.

\section{“Gachi” Rivero (Lima)}

Comediante de stand up comedy con más de 10 años de experiencia. Conductora de radio y televisión.

\section{Daniel San Roman (Lima)}

Comediante de stand up comedy con más de 5 años de experiencia. Gerente de Marketing en el Instituto San Ignacio de Loyola (ISIL)

Jorge Talavera (Lima)

Comunicador por la Universidad de Lima. Comediante con más de 5 años de experiencia.

\subsection{Casting de espacios}

Para la realización de este documental se contempló la posibilidad de realizar dos entrevistas. Una en el departamento de Walter Chullo, ya que resultaba ser el lugar más cómodo para una conversación larga. La segunda, se manejó la posibilidad de "El Cocodrilo Verde - Miraflores”, bar en el cual presentaba su monologo) y "La Posada del Mirador - Barranco" (Lugar donde Walter dicta sus clases). Al final se decidió por la segunda debido a temas de tiempo a disposición del loca. 
Casa de Walter Chullo
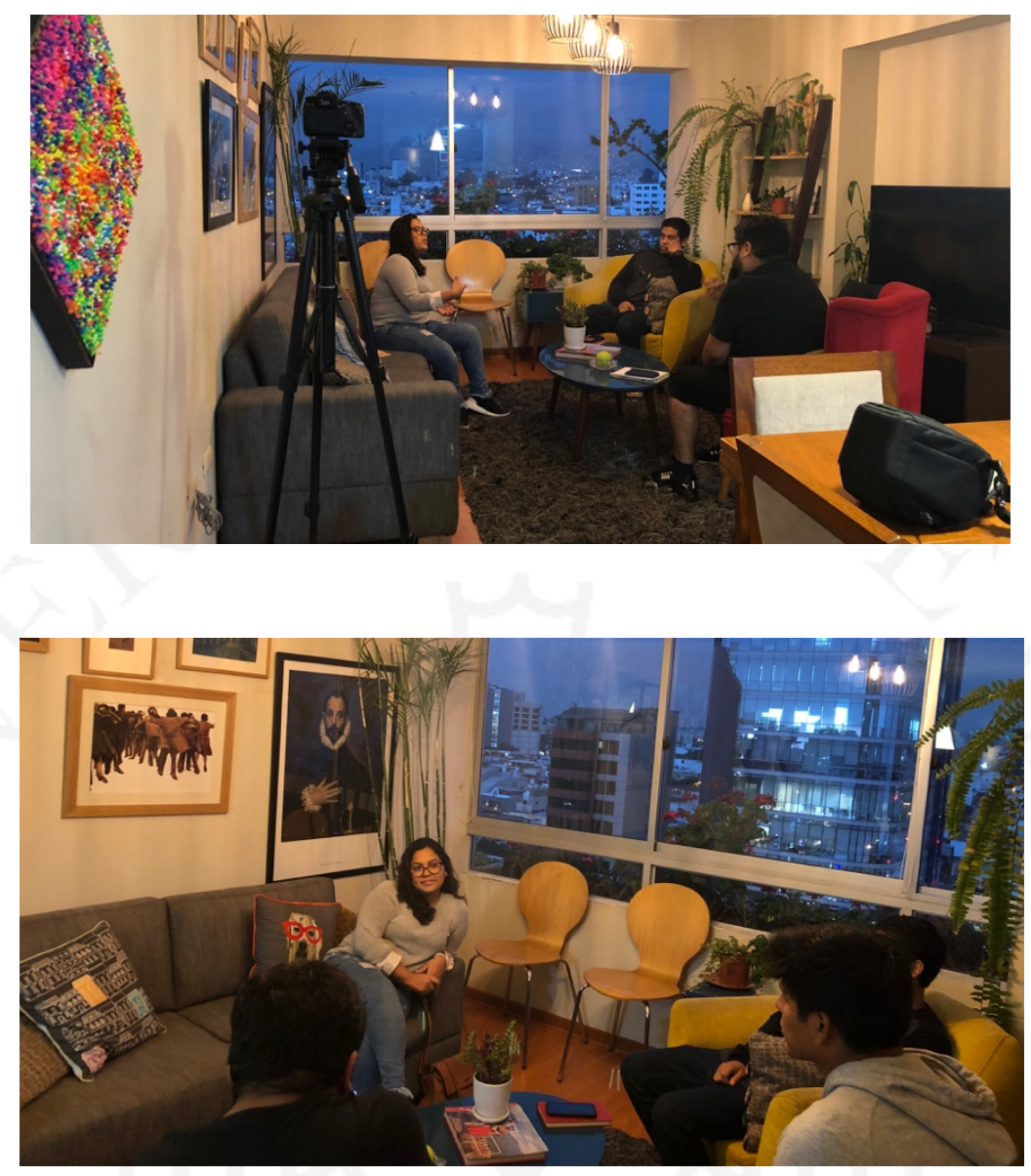

Cocodrilo Verde

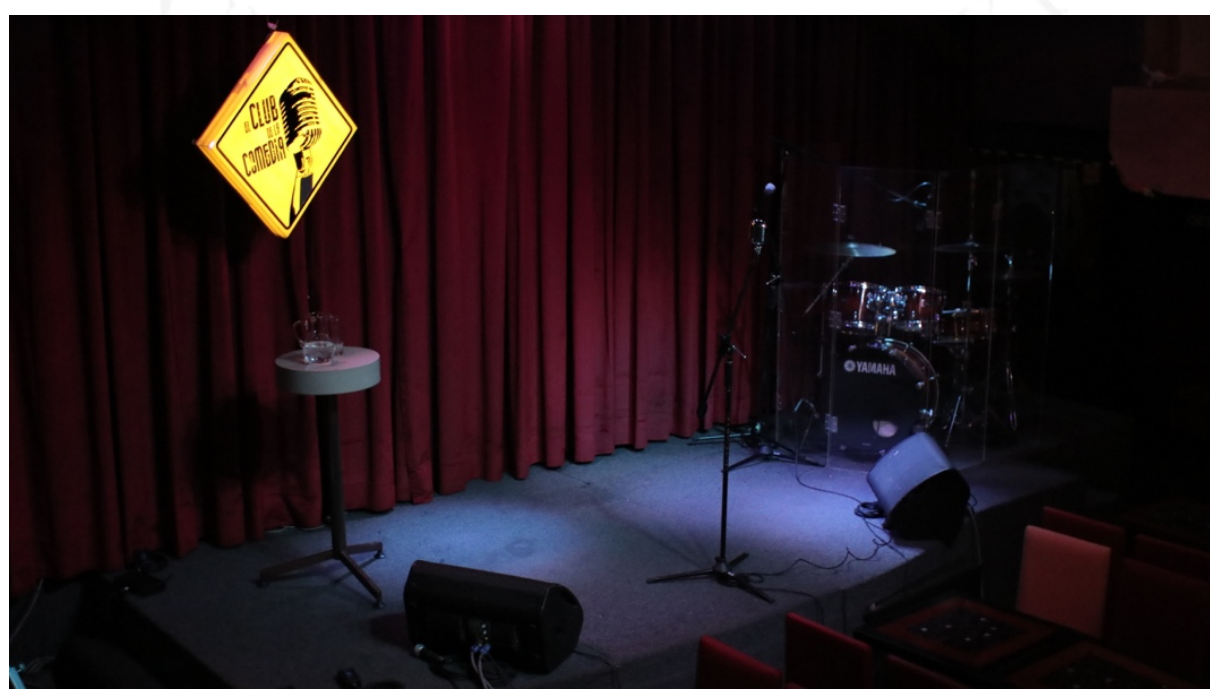




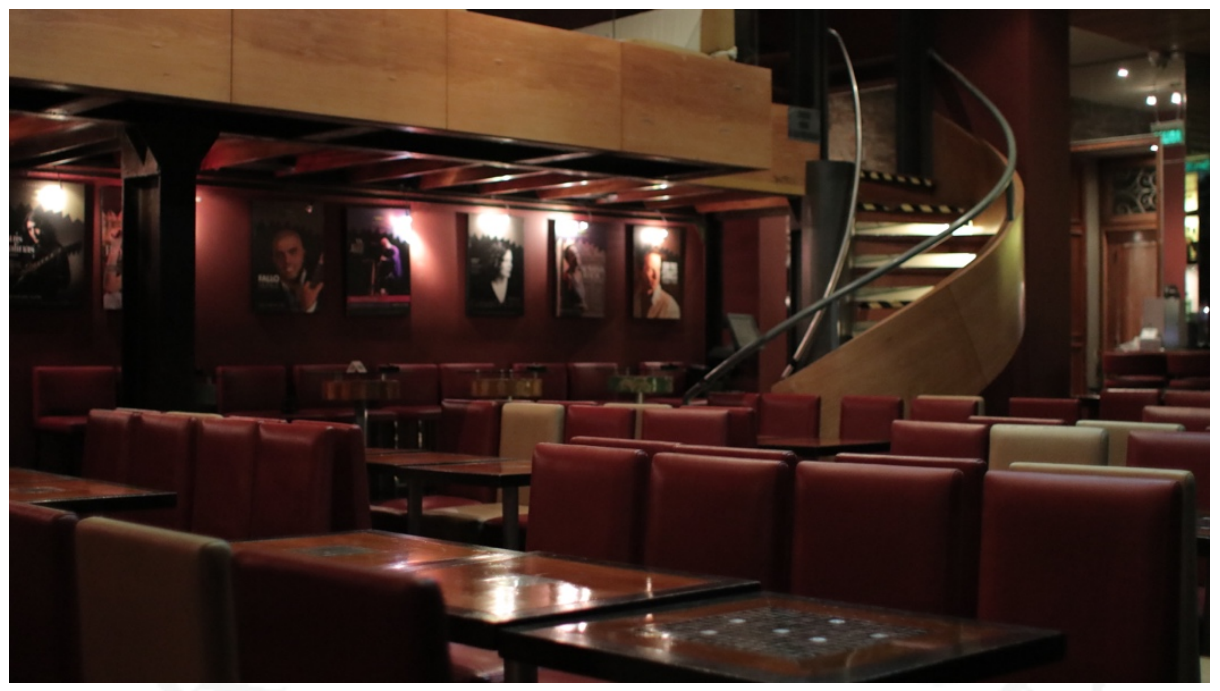

La Posada del Mirador

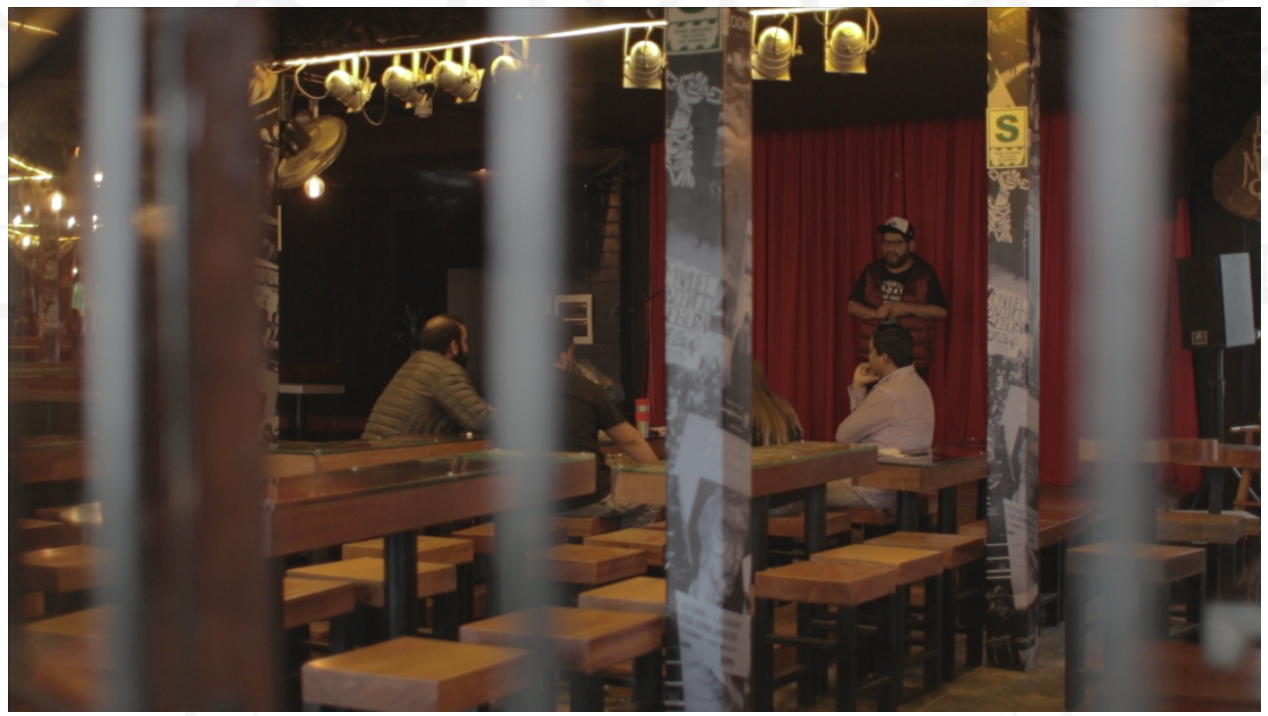

\subsection{Ficha técnica}

Título: Monólogos sobre la verdad

Año: 2019

Dirección: Paolo Ramirez

Cámara: Paolo Ramirez

Asistente de cámara: Ángel Fonseca

Edición: Paolo Ramirez 
Asistente de edición: Valeria Gómez

Producción: Valeria Gómez

Agradecimientos:

El Club de la Comedia Perú

La Posada del Mirador

Cocodrilo Verde

Link: https://vimeo.com/335747955 


\section{REFERENCIAS}

- Bruce, Jorge (2007). Nos habíamos choleado tanto: Psicoanálisis y racismo. Lima: Universidad de San Martin de Porres.

- Callirgos, Juan Carlos (1993). El racismo: la cuestión del otro (y de uno). Lima: Desco

- Carter, Judy. Stand up Comedy: The Book. (1989) Random House Publishing Group.

- De los Heros, Susana. (2016). Humor étnico y discriminación en La paisana Jacinta. Pragmática Sociocultural / Sociocultural Pragmatics, 4(1), pp. 74-107

- Heise, María (1994). Interculturalidad, un desafio. Lima: Centro Amazónico de Antropología y Aplicación Práctica $2^{\mathrm{a}}$ ed. corre. y aum.

- Instituto Nacional de Desarrollo de Pueblos Andinos, Amazónicos y Afroperuano. (2010). Aportes para un enfoque intercultural.

- León, Ramón y Tan, Juan José (1998). Humillados y ofendidos: un estudio acerca del desprecio y la discriminación en el Perú. Revista de Psicología de la PUCP. Vol. XVI, 1. $45-81$.

- Ley $\mathrm{N}^{\circ}$ 27270, Ley Contra Actos de Discriminación. (12 de mayo de 200). Recuperado del sitio de internet del Congreso de la República: http://www2.congreso.gob.pe/sicr/cendocbib/con4_uibd.nsf/30ABF17A7338F4 0E05257E2800764402/\$FILE/2_ley 27270_29_05_2000.pdf

- Ministerio de Cultura (2018). I Encuesta Nacional sobre Percepciones y Actitudes sobre Diversidad Cultural y Discriminación Étnico - Racial. Ipsos.

- Sánchez, Daniel (2010). Discriminación en medios de comunicación. Análisis de las bromas raciales en la televisión peruana. Lima: Palestra.

- UNESCO. (1960). Convención relativa a la Lucha contra las Discriminaciones en la esfera de la enseñanza. Paris. Recuperado de la biblioteca digital de UNESCO: https://unesdoc.unesco.org/ark:/48223/pf0000183342 